\title{
Electrical impedance spectroscopy measurements to estimate the uniaxial compressive strength of a fault breccia
}

\author{
SAIR KAHRAMAN ${ }^{1, *}$ and MICHAEL ALBER ${ }^{2}$ \\ ${ }^{1}$ Mining Engineering Department, Hacettepe University, Ankara, Turkey \\ ${ }^{2}$ Ruhr-University, Institute for Geology, Mineralogy and Geophysics, 44780 Bochum, Germany
}

MS received 20 December 2012; revised 30 April 2013

\begin{abstract}
Fault breccias are usually not suitable for preparing smooth specimens or else the preparation of such specimens is tedious, time consuming and expensive. To develop a predictive model for the uniaxial compressive strength (UCS) of a fault breccia from electrical resistivity values obtained from the electrical impedance spectroscopy measurements, twenty-four samples of a fault breccia were tested in the laboratory. The UCS values were correlated with corresponding resistivity values and a strong correlation between them could not be found. However, a strong correlation was found for the samples having volumetric block proportion (VBP) of 25-75\%. In addition, it was seen that VBP strongly correlated with resistivity. It was concluded that the UCS of the tested breccia can be estimated from resistivity for the samples having VBP of $25-75 \%$.
\end{abstract}

Keywords. Fault breccia; uniaxial compressive strength; electrical resistivity.

\section{Introduction}

Engineers working in different fields such as mining, geotechnical, civil, underground engineering as well as for oil, gas and minerals explorations have commonly used electrical measurements, which is one of the non-destructive geophysical methods. This method can be applied both in the laboratory and in the field. A.C. impedance spectroscopy (IS) is a powerful method of characterizing many electrical properties of materials and their interfaces with electronically conducting electrodes. This technique is becoming a popular analytical tool in materials research and development because it involves a relatively simple electrical measurement that can readily be automated and whose results may often be correlated with many complex materials variables from mass transport, rate of chemical reactions and dielectric properties to defects, microstructure and compositional influences on the conductance of solids (Macdonald and Johnson 1987).

Numerous researchers, especially those working in geophysics area, have investigated the electrical conductivity or resistivity of rocks in the laboratory for many years (Archie 1942; Brace et al 1965; Collett and Katsube 1973; Vinegar and Waxman 1984; Schmeling 1986; Jodicke 1990; Shankland and Waff 1997; Chelidze et al 1999; Shogenova et al 2001; Ara et al 2004; Kaselov and Shapiro 2004). However, a few researchers have

\footnotetext{
*Author for correspondence (sairkahraman@yahoo.com)
}

attempted to correlate resistivity with rock properties. Kate and Sthapak (1995) studied the engineering behaviour of certain Himalayan rocks and developed some empirical relations between rock strength and index test values. They found a logarithmic relation between resistivity and uniaxial compressive rock strength. Resistivity increases with increasing compressive strength. Bilim et al (2002) carried out electrical measurements on artificial rocks and found that compressive strength, tensile strength, point load strength and density strongly correlated with voltage drop. Kahraman and Alber (2006a) correlated the electrical resistivity values obtained from electrical impedance spectroscopy measurements with the corresponding physico-mechanical rock properties for eight different samples cored from a fault breccia. They found significant correlations between resistivity and physico-mechanical rock properties. Kahraman et al (2006) investigated the relation between electrical resistivity values and physicomechanical properties of igneous rocks and generally found strong correlations.

Some researchers (Chester and Logan 1986; Lindquist and Goodman 1994; Medley and Goodman 1994, Buergi et al 1999; Ehrbar and Pfenniger 1999; Goodman and Ahlgren 2000; Medley 2001, 2002; Habimana et al 2002; Laws et al 2003; Sonmez et al 2004, 2006) have investigated the characteristics of geologically complex rocks such as melanges, sheared serpentinites, coarse pyroclastic rocks and fault rocks. The reviews of these studies were presented by Kahraman and Alber (2006b) and will not be repeated here. There are no apparent predictive models except the authors' models in the literature for the 
geomechanical properties of fault breccias. Kahraman and Alber (2006b) and Alber and Kahraman (2009) correlated the uniaxial compressive strength (UCS) and elastic modulus $(E)$ values of Ahauser fault breccia (Germany) having blocks weaker than the matrix with volumetric block proportion (VBP) and texture coefficient (TC) and found strong correlations between UCS and both VBP and TC. In addition, Kahraman et al (2008) investigated the geomechanical properties of the Misis fault breccia from Turkey. As a result of multiple regression analysis, they found some significant alternative models including density, $P$ - and $S$-wave velocity and textural properties for the prediction of UCS and deviator stress. Kahraman et al (2009) also investigated the predictability of UCS and $E$ values of Misis fault breccia from some indirect methods using artificial neural networks (ANNs) and the results were compared with the regression models. They derived very good models for both UCS and E estimation from ANNs analysis compared with the regression models. VBP, density, $S$-wave velocity, the roundness of blocks and the average block diameter factor were included in the models. Slatalla et al (2010) performed acoustic emission measurements during the uniaxial compression tests on Misis fault breccia and showed that certain acoustic emission characteristics, such as cumulative amplitudes or amplitude frequencies, may be used to discriminate between different damage phenomena, i.e. between the different volumetric block proportions of a fault breccia. Kahraman et al (2010) investigated the usability of Cerchar abrasivity test for the determination of UCS and E of Misis fault breccia using ANNs analysis and concluded that the Cerchar abrasivity test is a useful tool for the prediction of UCS of Misis fault breccia. Recently, Coli et al (2011) carried out in situ shear tests to investigate the strength properties of the shalelimestone chaotic complex bimrock at the Santa Barbara disused open-pit mine (Italy). They showed that there was a good linear positive correlation between the volumetric block content and the friction angle, while cohesion seemed to be strongly affected by a critical volumetric block content threshold (20-25\%).

Determination of the UCS of rocks requires a large number of regularly shaped specimens. Fault breccias have very poor engineering properties and fall within the category of weak rocks. Weak rocks such as fault breccias are usually not suitable for preparing smooth specimens or else the preparation of such specimens is tedious, time consuming and expensive. Previous studies showed that there are some correlations between the electrical resistivity and rock strength. The electrical resistivity generally increases with increasing rock strength. Similarly, the electrical resistivity may also depend on VBP, and then there could be a strong relation between electrical resistivity and UCS. By contrast, the breccia consists of shale blocks and calcareous cement (calcite). It is known that calcite is much more resistive, and mineral and shales are more conductive compared to calcite, so prediction of VBP by resistivity measurement seems possible. Since the electrical resistivity is a relatively simple measurement, if a strong correlation between the electrical resistivity and the UCS of fault breccia is developed, it will be useful for the prediction purposes. In this study, it was aimed to develop a predictive model for the UCS of the Ahauser fault breccia by electrical resistivity. Electrical impedance spectroscopy method was used for measuring the electrical resistivity since it is an accurate and reliable way to measure the resistivity. Since there is no outcrop of the fault breccia, the research was conducted on the limited available core samples.

\section{Electrical impedance spectroscopy}

If a variable a.c. voltage is applied to a material, the ratio of voltage to current is known as the impedance. The a.c. impedance spectroscopy (IS) is a powerful method characterizing many electrical properties of materials and their interfaces with electronically conducting electrodes. It may be used to investigate the dynamics of bound or mobile charge in the bulk or interfacial regions of any kind of solid or liquid material: ionic, semi-conducting, mixed electronic-ionic and even insulators. IS is not only used in the academic laboratories, but also used in areas of industrial quality controls of paints, emulsions, electroplating, thin-film technology, materials fabrication, mechanical performance of engines, corrosion and so on. Although this technique is a highly popular analytical tool in materials research and development, it has some limitations and disadvantages: the instrumentation is sophisticated, expensive and sometimes difficult to use in the field. However, obtaining good-quality data at very low frequencies is not easy. Moreover, interpretation of the data can be difficult. However, recent advances in hardware and software control have made data collection and analysis much easier.

Collet and Katsube (1973) stated that at lower frequencies, particularly below $10^{3} \mathrm{~Hz}$, electrochemical polarization effects become important. At high frequencies, the effects of lead and especially the parasite capacities influence the impedance value. Conductivity and electrochemical polarization are closely related to moisture, state of moisture (frozen or liquid state), rock fabrics anisotropy and mineral content. Borner et al (1996) showed that complex electrical rock properties, such as frequency effect or the phase angle, may be obtained from IS measurements. Complex electrical rock properties depend on the pore space geometry and the microstructure of the internal rock boundaries. For this reason, these rock properties contain information about rock permeability and fluid properties in the pore space. Chelidze et al (1999) analysed the existing theories of polarization of heterogeneous media and stated that IS can be useful for the 
interpretation of frequency spectra of complex dielectric permittivity or conductivity of water-bearing rocks and porous material in general, and for the determination of water content, its thermodynamic state, the connectivity of water-bearing channels and their correlation lengths and the surface to volume ratio and surface charge in particular, in addition to the traditional formation factor, which is obtained from ohmic conductivity measurements.

\section{Geology and sampling}

Samples of $101.3 \mathrm{~mm}$-diameter cores were taken from Ahauser dam near Attendorn in Northrhine-Westfalia, Germany. The Devonian (Givet) strata consist of reddish, greyish and brownish shale, fine-grained sandstone with varying contents of calcite, with massive limestone in reef facies on the top. Figure 1 shows a geologic map of the area and a cross section. Cemented tectonic breccia consists of slate components of various dimensions and recrystallized limestone.

Only 12 available core samples among the stored samples were found and were taken for the study. The length of cores ranges from 15 to $29 \mathrm{~cm}$. In the laboratory, for

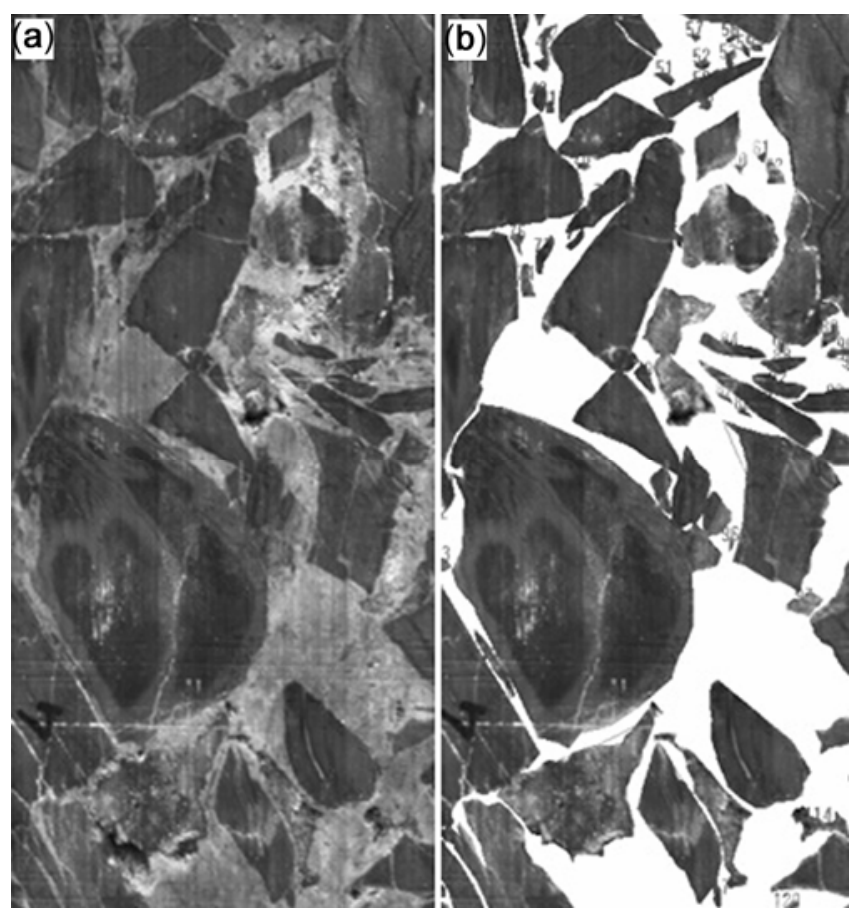

Figure 1. (a) Geologic map of the area around drillhole $\mathrm{DH} / 65^{\circ}$, where the breccia has been recovered. Note the location of the drillhole exactly along the strike-slip fault. (b) A-B cross-section perpendicular to the thrust fault indicating the inclination of the drillhole (Legend: $d v-a D$ : reef limestone, fine to medium grained, blue-grey, partly dolomitized; dvN1 + G: Newberrien and Grevensteiner beds, silty slate, high mica content, slightly calcareous, grey to green; dvW: Wiedenester beds, slate and siltstone, grey to brown) (Slatalla 2004). the strength and resistivity tests, in addition to the two $101.3 \mathrm{~mm}$-diameter cores, only twenty-two samples having diameters of $7 \cdot 6-73.0 \mathrm{~mm}$ could be cored from eight $101.3 \mathrm{~mm}$-diameter cores to obtain the samples having different volumetric block proportion.

\section{Estimating volumetric block proportion}

VBP is the total volume of blocks divided by the total volume of the rock mass. Some researchers (Medley and Goodman 1994; Medley 1997, 2002; Haneberg 2004) have investigated and discussed the uncertainties in estimating three-dimensional block size distributions from one- or two-dimensional measurements.

Sieve analysis, which is a three-dimensional method for the determination of VBP, is not possible for the fault breccia tested in this study since the blocks and matrix are welded together. For this reason, image analysis method on the scanned images of the circumferential surfaces of the cores was used for the estimation of VBP. As explained in accompanying paper (Kahraman and Alber 2006b), the blocks have approximately same dimensions in two- and three-dimensional measurements for the tested fault breccia.

Medley and Lindquist (1995) suggested the block/ matrix threshold as $5 \%$ of a characteristic engineering dimension, such as tunnel diameter, landslide height or core diameter. The blocks smaller than the block/matrix threshold dimension can be accepted as matrix, and have negligible effect on the rock strength. In this study, the largest block size in each core was selected as the characteristic engineering dimension.

The circumferential surfaces of cores were scanned by DMT CoreScan II. Scanned images were analysed using image processing software. Figures 2 and 3 show the original and processed images of the samples having a VBP of 70.7 and $50 \cdot 4 \%$, respectively. Further information on the estimation of VBP can be found in Kahraman and Alber (2006b).

\section{Laboratory studies}

\subsection{Electrical impedance spectroscopy measurements}

Resistivity measurements were performed on 24 core samples having different diameters ranging from 7.6 to $101.3 \mathrm{~mm}$ (figure 4). End surfaces of the cores were cut parallel and polished sufficiently to a smooth plane. In addition, both end surfaces of the cores were painted with conductive silver paint to provide good coupling. The samples were generally weak. Therefore, to prevent the possible disintegration of the samples, saturation or drying was not applied, i.e. tested samples were air-dried. Circular stainless steel electrodes were used in the tests in which a two-electrode technique was employed. The samples 
were fixed between electrodes using a hydraulic ram. To ensure good contact between the electrodes and samples, approximately $1 \mathrm{MPa}$ stress was applied.

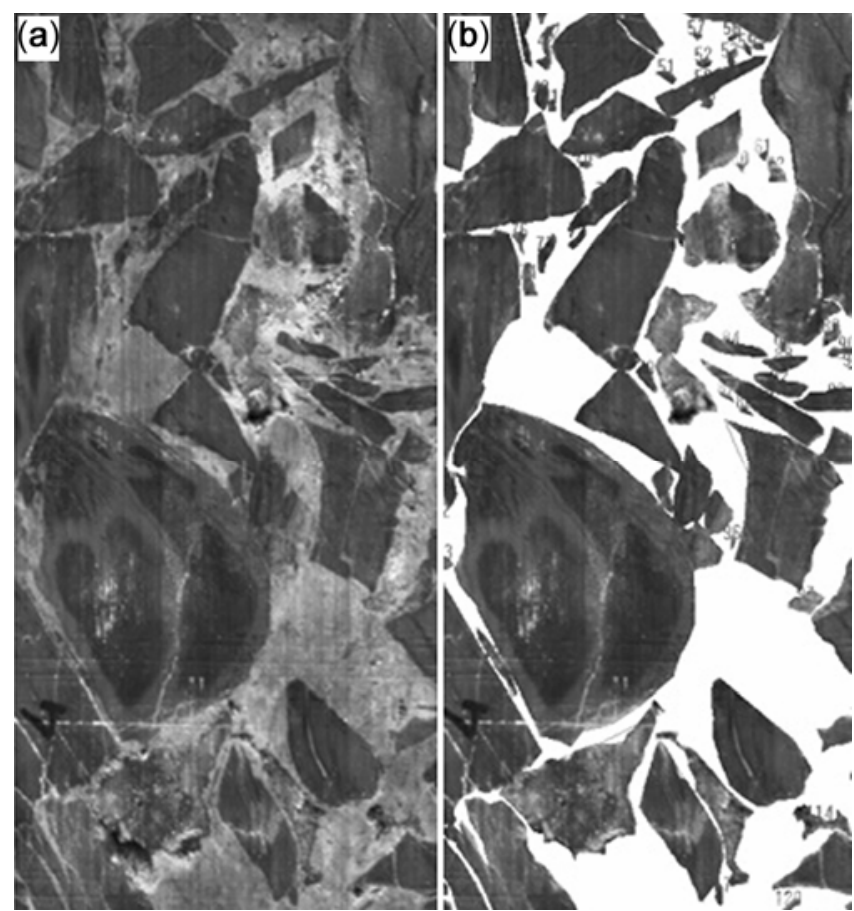

Figure 2. (a) Original and (b) processed images of a sample having a VBP of $70 \cdot 7 \%$.
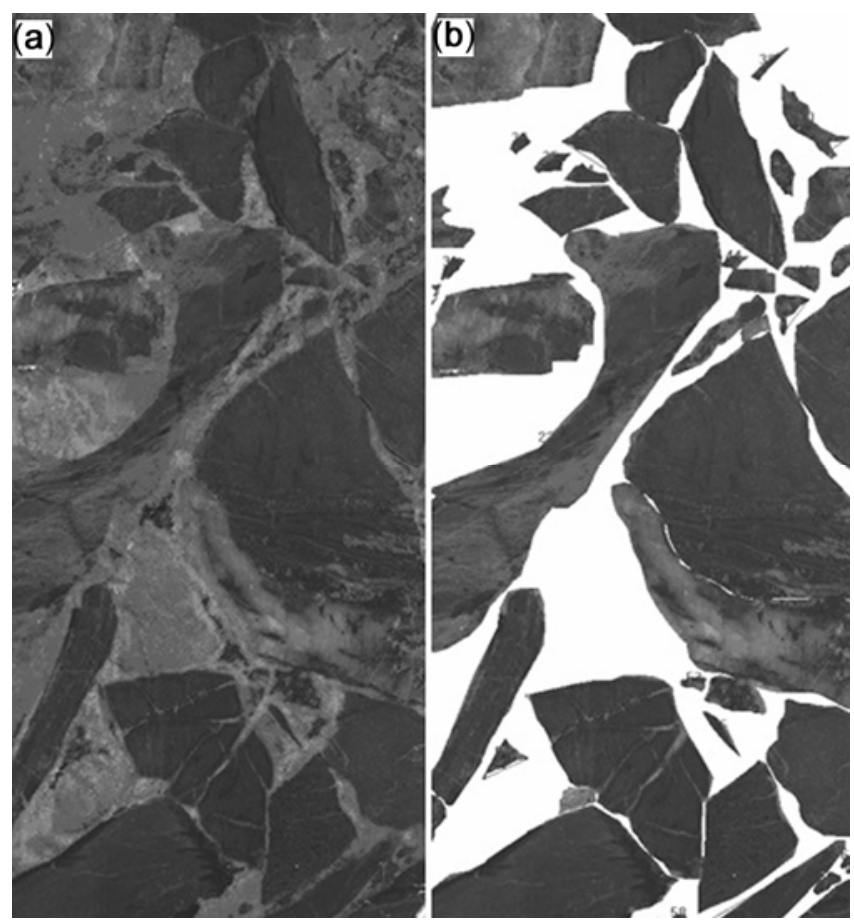

Figure 3. (a) Original and (b) processed images of a sample having a VBP of $50 \cdot 4 \%$.
A computer-controlled impedance analyser, Solartron SI-1260 coupled with dielectric interface model SI-1296, was used for the resistivity measurements. This impedance analyser generates a sine wave signal, whose frequency can be varied, and measures both the real and imaginary impedances of the tested sample. A.C. voltage with frequency ranging from $1 \mathrm{~Hz}$ to $10 \mathrm{MHz}$ was applied across the rock sample and its response was measured at room temperature.

Figure 5 indicates the Bode plot of a sample tested. As shown in figure 5 , when phase angle $(\theta)$ decreases with increasing frequency, impedance rapidly decreases with increasing frequency at low-frequency values. Then, it gradually decreases and becomes stable beyond a threshold frequency, corresponding to $\theta$, is approximately zero. This stable value is equal to the resistance. A resistance value of $2.41 \times 10^{5} \Omega$ may be extracted from figure 5 . The high impedance at low-frequency values is due to the polarization effect at the interface of the electrodes and sample.

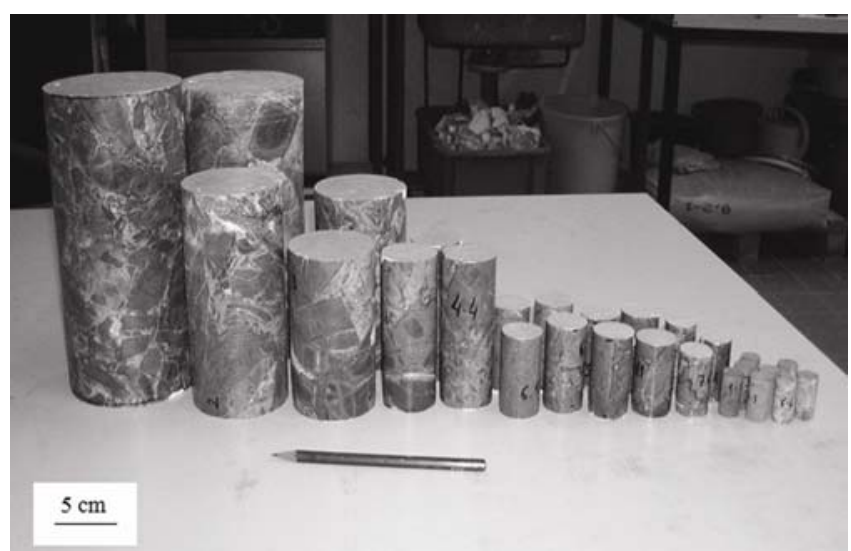

Figure 4. Tested samples.

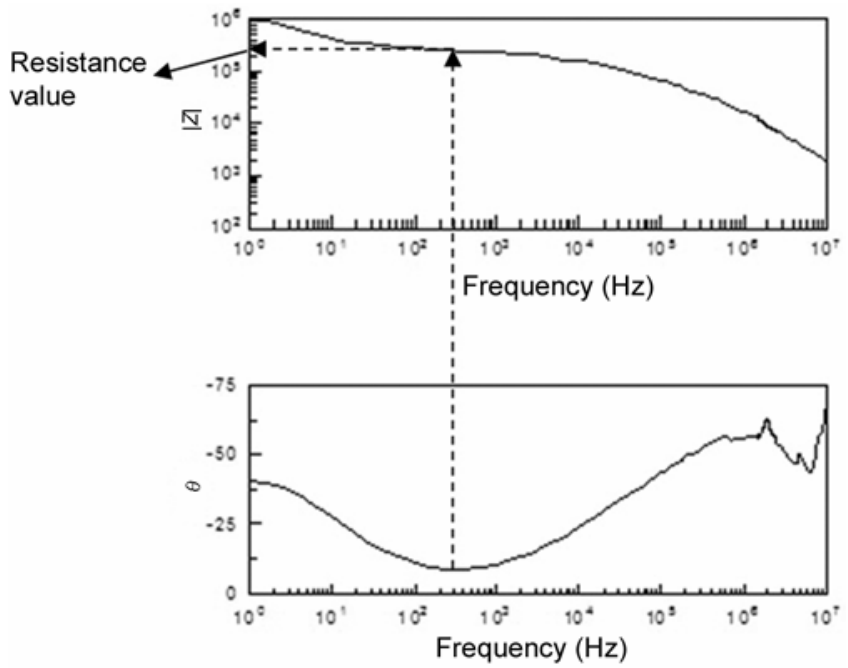

Figure 5. Bode plot of the sample no. 2. 


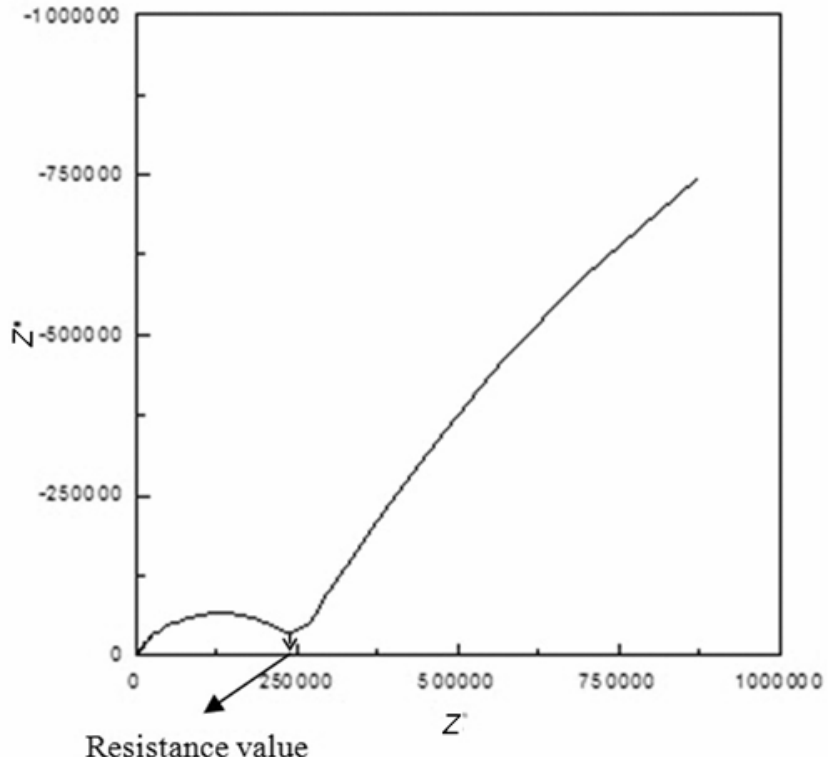

Figure 6. Complex plane plot for the sample in figure 5.

Complex plane plot for the same sample is shown in figure 6. As stated earlier, when the frequency is increased to the left side of the plot, the phase angle is decreased. The intersection of the impedance curve with the abscissa corresponds to $\theta=0$, which means the imaginary part of impedance is zero. The real part of the impedance is equal to the impedance and this value also equals to the resistance. A resistance value of $2.41 \times 10^{5} \Omega$ can be derived from figure 6 . This value is the same as the value obtained from figure 5 .

Using the resistance and the geometry of the samples, resistivity values were calculated from the following equation

$$
\rho=\frac{R A}{L},
$$

where $\rho$ is the electrical resistivity, $R$ the resistance, $A$ cross-sectional area of specimen and $L$ the length of specimen.

\subsection{Uniaxial compressive strength test}

The two of tested samples were original $101 \cdot 3 \mathrm{~mm}$ cores. Twenty-two smaller samples were cored from the other original $101.3 \mathrm{~mm}$ cores. ISRM (1981) suggests that the diameter of the cores should be about 10 times the maximum grain size in each sample. However, it is not possible to satisfy this condition for breccias or other bimrocks. Most of the cores had a height to diameter ratio of 2-2.5. Some cores could not be prepared in standard dimensions, because of core breakage due to the weak structure of the breccia. The UCS values of the samples having a height to diameter ratio of less than 2 were corrected using the following formula suggested by Protodyakonov (1969)

$$
\mathrm{UCS}=\frac{8 \mathrm{UCS}_{1}}{7+2 d / h},
$$

where UCS is the standard uniaxial compressive strength $(\mathrm{MPa}), \mathrm{UCS}_{1}$ the measured uniaxial compressive strength (MPa), $d$ the core diameter (mm) and $h$ the core height (mm).

After trimming the end surfaces of the cores, uniaxial compression tests were performed using an electrohydraulic servo-controlled stiff-testing machine (MTS). The details of the uniaxial compressive strength tests can be found in Kahraman and Alber (2006b).

\section{Results and discussion}

VBP, UCS and resistivity values of the tested samples are given in table 1 . The VBP of the samples ranges from $7 \cdot 2$ to $96.6 \%$. UCS values indicate a wide range (from 9.8 to86.6 MPa). Resistivity values vary between 3.2 and $24677.4 \mathrm{k} \Omega \mathrm{m}$.

The UCS values were correlated with the resistivity values. The correlation between UCS and resistivity is not strong as shown in figure 7. It is thought that the lack of the correlation is related with the VBP. Lindquist and Goodman (1994) and Lindquist (1994) have identified a conservative relation between strength and VBP for melange bimrocks. The strength of a melange is that of the matrix below 25\% VBP. The friction angle of the melange proportionally increases with increasing VBP between 25 and 75\% VBP. Above 75\% VBP, the blocks tend to touch and there is no further increase in melange strength. The findings of Lindquist and Goodman (1994) and Lindquist (1994) can be applied to the breccia tested in this study. It is expected that the resistivity values for the samples having VBP of below about 25\% are similar, since they can be accepted as matrix. However, the resistivity values for the samples having VBP below about $25 \%$ vary widely. This is probably because the matrix of the breccia composed of recrystallized limestone has secondary calcite crystals. If a matrix sample has a high content of calcite crystal, it will show high resistivity value, since calcite crystals have high electrical resistance. In addition, it was seen that the resistivity values for the samples having VBP of above $75 \%$ are scattered. As stated earlier, breccia samples are composed of varying contents of reddish, greyish and brownish shale blocks, and recrystallized limestone. It was observed that some samples having high VBP may have dominantly reddish, greyish or brownish shale blocks. Therefore, the samples having the same VBP may have different resistivity values. A strong correlation between UCS and resistivity for the samples having VBP between 25 and $75 \%$ was found (figure 8). The relation follows a linear function. The equation of the line is

$$
\mathrm{UCS}=0.0048 \rho+11.89 \quad r^{2}=0.93,
$$


Table 1. Volumetric block proportion, compressive strength and resistivity values.

\begin{tabular}{lcccr}
\hline $\begin{array}{l}\text { Sample } \\
\text { no. }\end{array}$ & $\begin{array}{c}\text { Sample diameter } \\
(\mathrm{mm})\end{array}$ & $\begin{array}{c}\text { Volumetric block } \\
\text { proportion }(\%)\end{array}$ & $\begin{array}{c}\text { Compressive } \\
\text { strength }(\mathrm{MPa})\end{array}$ & $\begin{array}{r}\text { Resistivity } \\
(\mathrm{k} \Omega \mathrm{m})\end{array}$ \\
\hline 1 & $101 \cdot 3$ & $70 \cdot 0$ & $12 \cdot 1$ & $23 \cdot 6$ \\
2 & $101 \cdot 3$ & $75 \cdot 0$ & $16 \cdot 1$ & $9 \cdot 4$ \\
3 & $73 \cdot 0$ & $76 \cdot 7$ & $20 \cdot 6$ & $113 \cdot 6$ \\
4 & $73 \cdot 0$ & $77 \cdot 0$ & $15 \cdot 5$ & $196 \cdot 5$ \\
5 & $62 \cdot 6$ & $54 \cdot 5$ & $13 \cdot 1$ & $1067 \cdot 4$ \\
6 & $43 \cdot 6$ & $70 \cdot 7$ & $17 \cdot 7$ & $1699 \cdot 0$ \\
7 & $40 \cdot 5$ & $94 \cdot 4$ & $15 \cdot 1$ & $10 \cdot 1$ \\
8 & $37 \cdot 8$ & $68 \cdot 3$ & $13 \cdot 5$ & $257 \cdot 3$ \\
9 & $30 \cdot 1$ & $74 \cdot 6$ & $11 \cdot 5$ & $285 \cdot 0$ \\
10 & $30 \cdot 1$ & $50 \cdot 4$ & $47 \cdot 2$ & $7033 \cdot 6$ \\
11 & $30 \cdot 1$ & $77 \cdot 6$ & $41 \cdot 1$ & $9 \cdot 5$ \\
12 & $30 \cdot 1$ & $76 \cdot 3$ & $9 \cdot 8$ & $2652 \cdot 5$ \\
13 & $24 \cdot 4$ & $56 \cdot 0$ & $33 \cdot 8$ & $3312 \cdot 7$ \\
14 & $24 \cdot 4$ & $23 \cdot 1$ & $26 \cdot 0$ & $11091 \cdot 3$ \\
15 & $24 \cdot 4$ & $88 \cdot 2$ & $11 \cdot 9$ & $2388 \cdot 9$ \\
16 & $24 \cdot 4$ & $96 \cdot 6$ & $23 \cdot 5$ & $3 \cdot 2$ \\
17 & $24 \cdot 4$ & $22 \cdot 8$ & $34 \cdot 8$ & $9059 \cdot 2$ \\
18 & $24 \cdot 4$ & $28 \cdot 5$ & $34 \cdot 6$ & $5424 \cdot 8$ \\
19 & $14 \cdot 5$ & $23 \cdot 8$ & $43 \cdot 4$ & $9657 \cdot 2$ \\
20 & $14 \cdot 5$ & $18 \cdot 2$ & $70 \cdot 1$ & $5646 \cdot 1$ \\
21 & $7 \cdot 6$ & $7 \cdot 8$ & $77 \cdot 2$ & $12317 \cdot 3$ \\
22 & $7 \cdot 6$ & $7 \cdot 2$ & $63 \cdot 8$ & $24677 \cdot 4$ \\
23 & $7 \cdot 6$ & $10 \cdot 6$ & $47 \cdot 1$ & $21992 \cdot 5$ \\
24 & $7 \cdot 6$ & $8 \cdot 5$ & $86 \cdot 6$ & $9399 \cdot 2$ \\
\hline
\end{tabular}

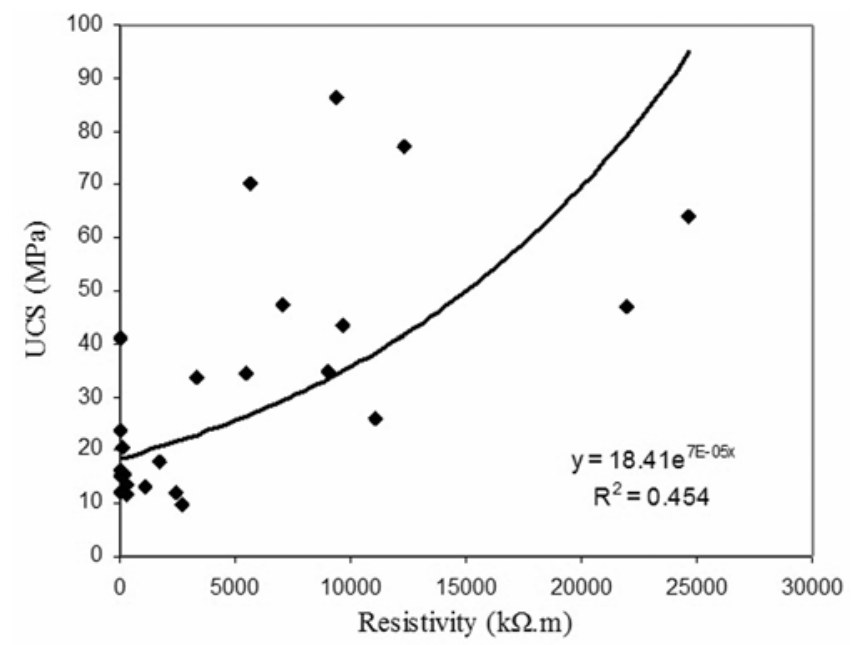

Figure 7. The relation between UCS and resistivity.

where UCS is the uniaxial compressive strength (MPa) and $\rho$ the electrical resistivity $(\mathrm{k} \Omega \mathrm{m})$.

The limitation of VBP between 25 and $75 \%$ excludes 14 samples of 24 samples in total. However, this does not indicate the correlation is accidental. As stated earlier, some researchers showed that when a rock containing clasts have a VBP between 25 and 75\%, a clear statement can be said of its strength. For this reason, the derivation of a strong correlation between UCS and resistivity for the samples having VBP between 25 and $75 \%$ is an expected result. It also tested the validation of (3) by the $F$-test and

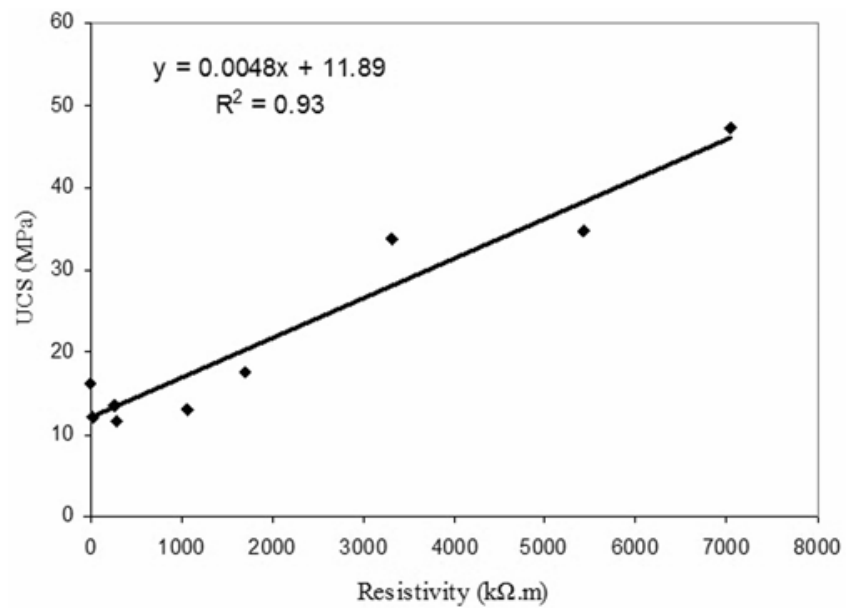

Figure 8. The relation between UCS and resistivity for the rocks having VBP of $25-75 \%$.

the $t$-test. It was seen that (3) is significant according to the $F$-test and the $t$-test.

In addition, the relation between VBP and resistivity was studied and a strong correlation between the two parameters was found (figure 9). The equation of the exponential relation is

$$
\mathrm{VBP}=72 \cdot 27 \mathrm{e}^{-0.0001 \rho} \quad r^{2}=0 \cdot 78,
$$

where VBP is the volumetric block proportion and $\rho$ the electrical resistivity $(\mathrm{k} \Omega \mathrm{m})$. 


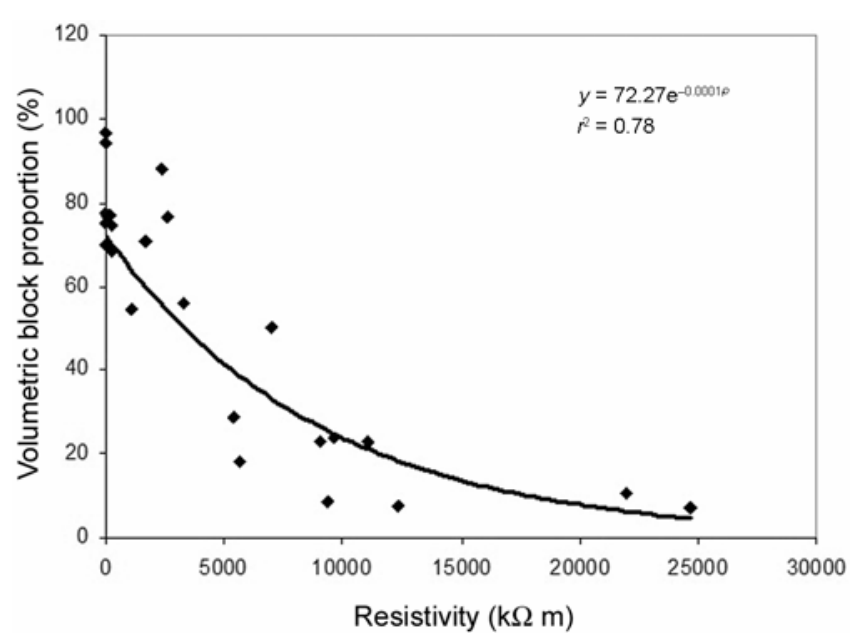

Figure 9. The relation between VBP and resistivity.

One may think that the lack of correlation between UCS and resistivity for all data is due to sample size being small relative to block size and the consequences of that on both the resistivity and UCS measurements. This thought is not true. For example, there is no effect of blocks on the strength and resistivity for those below about 25\% VBP. As it was shown in figures 7 and 9, high-strength samples having below 25\% VBP show highly scattered resistivity values. As stated earlier, the scattering of resistivity values as a result of varying contents of secondary calcite crystals in the matrix.

\section{Conclusions}

Twenty-four samples of a fault breccia were tested in the laboratory to develop a predictive model for the UCS from electrical resistivity values obtained from the electrical impedance spectroscopy measurements. The data were evaluated using regression analysis. A strong correlation between UCS and resistivity could not be found for all data. It is thought that the reason for the lack of correlation is probably related to the VBP. For this reason, regression analysis was repeated for the samples having VBP between 25 and $75 \%$ and a strong correlation was found between UCS and resistivity. In addition, since the VBP is an important parameter for fault breccias, the relation between VBP and resistivity was investigated. Then, it was seen that VBP strongly correlated with resistivity.

In conclusion, the VBP of the tested breccia can be estimated from resistivity. The UCS of the tested breccia can only be estimated from resistivity for the samples having VBP between 25 and 75\%.

\section{Acknowledgements}

This study was supported by Alexander von Humboldt Foundation. Authors thank Prof Dr Jörg Renner and
Dr Jan ter Heege for help and suggestions on the electrical impedance measurements.

\section{References}

Alber M and Kahraman S 2009 Rock Mech. Rock Eng. 42117

Ara T, Bjorndalen N, Talabani S and Islam M R 2004 EEC Innovation 220

Archie G E 1942 Trans. Amer. Inst. Min Metall. Petrol. Eng. 14654

Bilim N, Ozkan I and Gokay M K 2002 Determination of discontinuities at rock materials by electrical resistance method. In Proc. 7th Regional Rock Mech. Symp. (eds) C Sensogut and I Ozkan (Ankara: Kozan Ofset)

Borner F D, Schopper J R and Weller A 1996 Geophys. Prosp. 44583

Buergi C, Parriaux A, Franciosi G and Rey J-Ph 1999 Eng. Geol. 51225

Brace W F, Orange A S and Madden T R 1965 J. Geophys. Res. 705669

Chelidze T L, Gueguen Y and Ruffet C 1999 Geophys. J. Int. 13716

Chester F M and Logan J M 1986 Pure Appl. Geophys. 12479

Collett L S and Katsube T J 1973 Geophysics 3876

Coli N, Berry P and Boldini D 2011 In. J. Rock Mech. Min. Sci. 4895

Ehrbar H and Pfenniger I 1999 In Vorerkundung und Prognose der Basistunnels am Gotthard und am Lötschberg (Rotterdam: Balkema Press)

Goodman R E and Ahlgren C S 2000 J. Geotech. Geoenviron. Eng. 126429

Habimana J, Labiouse V and Descoeudres F 2002 J. Rock Mech. Min. Sci. 39677

Haneberg W C 2004 Felsbau-Rock Soil Eng. 2219

ISRM 1981 ISRM suggested methods (ed.) E T Brown (Oxford: Pergamon Press)

Jodicke H 1990 Zonen hoher elektrischer Krustenleitfahigkeit im Rhenoherzynikum and seinem nordlichen Vorland. $\mathrm{PhD}$ thesis, Münster University

Kahraman S and Alber M 2006a J. Rock Mech. Min. Sci. 43543

Kahraman S and Alber M 2006b J. Rock Mech. Min. Sci. 431277

Kahraman S, Ogretici E, Yeken T and Fener M 2006 In EUROCK'06, Europ. Regional ISRM Symp. (eds) Van Cotthem, Charlier, Thimus and Tshibangu (London: Taylor \& Francis Group)

Kahraman S, Alber M, Fener M and Gunaydin O 2008 J. Rock Mech. Min. Sci. 451469

Kahraman S, Gunaydin O, Alber M and Fener M 2009 Exp. Syst. Appl. 366874

Kahraman S, Alber M, Fener M and Gunaydin O 2010 Exp. Syst. Appl. 378750

Kaselov A and Shapiro S A 2004 J. Geophys. Eng. 11

Kate J M and Sthapak A K 1995 In Proc. 35th US Symp. Rock Mech. (eds) J J K Daemen and R A Schultz (Rotterdam: Balkema Press)

Laws S, Eberhardt E, Loew S and Descoeudres F 2003 Rock Mech. Rock Eng. 36271 
Lindquist E S 1994 The strength and deformation properties of melange. PhD thesis, University of California at Berkeley, California

Lindquist E S and Goodman R E 1994 In Proc.1st North Amer. Rock Mech. Symp. (eds) P P Nelson and S E Laubach (Rotterdam: Balkema Press)

Macdonald J R and Johnson W B 1987 In Impedance spectroscopy (ed.) J R Macdonald (New York: John Wiley and Sons Press)

Laws S, Eberhardt E, Loew S and Descoeudres F 2003 Rock Mech. Rock Eng. 36271

Medley E W and Goodman R E 1994 In Proc. 1st North Amer. Rock Mech. Sym. (eds) P P Nelson and S E Laubach (Rotterdam: Balkema Press)

Medley E W and Lindquist E S 1995 In Proc. 35th US Rock mech. Symp. (eds) J K Daemen and R A Schultz (Rotterdam: Balkema Press)

Medley E W 1997 In Proc. Int. Symp. Engin. Geol. Env. (eds) P G Marinos, G C Koukis, G C Tsiambaos and G C Stournaras (Rotterdam: Balkema Press)
Medley E W 2001 Felsbau-Rock Soil Eng. 1920

Medley E W 2002 In Proc. 5th North Amer. Rock Mech. Symp. (eds) R Hammah, W Bawden, J Curran and M Telesnicki (Toronto: University of Toronto Press)

Protodyakonov M M 1969 In Mechanical properties of rocks (eds) M M Protodyakonov et al (translated from Russian, Jerusalem: Israel Program for Scientific Translations)

Schmeling H 1986 Phys. Earth Planet. Int. 43123

Shankland T J and Waff H S 1997 J. Geophys. Res. 825409

Shogenova A, Joeleht A, Kirsimae K, Sliaupa S, Rasteniene V and Babele A 2001 In Proc. 6th Nordric Symp. Petrophysics (eds) $\mathrm{K}$ Backe and $\mathrm{T}$ Loermans (Trondheim: Norwegian University of Science and Technology)

Slatalla N, Alber M and Kahraman S 2010 Bull. Eng. Geol. Environ. 69455

Sonmez H, Gokceoglu C, Tuncay E, Medley E W and Nefeslioglu H A 2004 Felsbau-Rock Soil Eng. 2227

Sonmez H, Gokceoglu C, Medley E W, Tuncay E and Nefeslioglu H A 2006 J. Rock Mech. Min. Sci. 43554

Vinegar H J and Waxman M H 1984 Geophysics 491267 